\title{
Perspective on models in theoretical and practical traditions of knowledge: The example of Otto engine animations
}

\author{
Jesper Haglund and Helge Strömdahl
}

\section{Linköping University Post Print}

N.B.: When citing this work, cite the original article.

The original publication is available at www.springerlink.com:

Jesper Haglund and Helge Strömdahl, Perspective on models in theoretical and practical traditions of knowledge: The example of Otto engine animations, 2012, International journal of technology and design education, (22), 3, 311-327.

http://dx.doi.org/10.1007/s10798-010-9146-0

Copyright: Springer Verlag (Germany) http://www.springerlink.com/?MUD=MP

Postprint available at: Linköping University Electronic Press http://urn.kb.se/resolve?urn=urn:nbn:se:liu:diva-79922 


\title{
Perspective on models in theoretical and practical traditions of knowledge - the example of Otto engine animations
}

\author{
Jesper Haglund* and Helge Strömdahl \\ Swedish National Graduate School in Science and Technology Education, \\ Linköping University, \\ S-601 74 Norrköping, Sweden \\ * Phone: +4611363364 \\ * Fax: +46 11363029 \\ *E-mail: jesper.haglund@liu.se
}

\begin{abstract}
Nineteen informants $(n=19)$ were asked to study and comment two computer animations of the Otto combustion engine. One animation was non-interactive and realistic in the sense of depicting a physical engine. The other animation was more idealised, interactive and synchronised with a dynamic PV-graph. The informants represented practical and theoretical traditions of knowledge: science students and teachers at upper secondary school level; vocational students and teachers in vehicle mechanics at upper secondary school level, and; MSc and PhD students in vehicle system engineering. The aim was to explore how they interpreted the animations against the background of their different traditions of knowledge and their experience of physical engines and models of engines. A key finding was that the $\mathrm{PhD}$ students saw the interactive animation as a familiar and useful model of engines, whereas the vehicle mechanics teachers saw it as a poor representation of reality. One of the vehicle mechanics teachers tried to match the model with a physical engine, a line of reasoning similar to Diesel's development program. A general conclusion was that there is a variety of competent ways to interpret a model, depending on the tradition of knowledge.
\end{abstract}

Keywords: Traditions of knowledge; Modelling; Computer animation;

Thermodynamics; Combustion engine

(To be published in Journal of Technology and Design Education) 


\section{Introduction}

France, Compton and Gilbert (2010) claim that modelling is a key practice of both science and technology, although with important differences. A focus on modelling "provides an opportunity to explore differences between technology and science particularly differences in purpose, outcome and the underlying reasoning that supports these two disciplines. /.../For technology the purpose is a designed intervention whose outcome is judged by its successful function. This activity is powered by the cognitive processes of functional and practical reasoning. The purpose of science is to explain phenomena, where the explanation is judged by its ability to make sense of empirical evidence." As an example, they present the stories of two biotechnologists, representing two different disciplines: "What was most striking about Robert the technologist and Allen the scientist was the nature of the expertise they brought to their activities. We argue that these individuals were defined by the practice of their disciplines and this in turn defined their purpose, actions and thinking."

Few studies have been performed on teachers' and students' ideas of the role of modelling in technology (France et al. 2010). The relevance of conducting such studies is emphasised by a recent Delphi study, where experts ranked modelling as the third most important concept to be taught in technology and engineering education (Rossouw et al.). As a contrast, empirical studies have been made on ideas of modelling in science education. Grosslight et al. (1991) performed an interview study on the conception of models and their use in science among students and experts. While $7^{\text {th }}$ graders saw models as toys or copies of reality, some of the $11^{\text {th }}$ graders realised that somebody had created the model and that this modeller had to make conscious decisions in simplification and high-lighting of certain characteristics. Only experts, however, acknowledged that models serve to develop and test ideas, rather than being copies of reality and that modelling involves evaluation of several designs, with regards to how well they serve the intended purpose of the model. In their analysis of the views on the nature of models among 39 science teachers, Justi and Gilbert (2003) found that only the teachers with degrees in chemistry or physics "were able to discuss the notion of model in a more comprehensive way, often consistently close to an accepted scientific viewpoint" (ibid.). These teachers were more likely than the teachers with biology or no degrees to recognise that a model can be changed and may be one of several possible models. 
Harrison and Treagust (2000) see practical obstacles to the use of models in education: "Modelling is the essence of thinking and working scientifically. But how do secondary students view science models? Usually as toys or miniatures of real-life objects with few students actually understanding why scientists use multiple models to explain concepts.” However, Black (1962) calls for humility when giving a possible explanation of this everyday life view of models:

To speak of 'models' in connection with a scientific theory already smacks of the metaphorical. Were we called upon to provide a perfectly clear and uncontroversial example of a model, in the literal sense of the word, none of us, I imagine, would think of offering Bohr's model of the atom, or a Keynesian model of an economic system.

The empirical studies mentioned above relate to a comparatively linear progression on the view of models. They start out from the pre-school knowledge, follow students throughout their science education, science teachers and finally scientists, which are, perfectly appropriately, seen as experts in scientific modelling. In the present study, this progression in the theoretical science tradition is regarded in parallel with the development of knowledge in a practical tradition of knowledge, where scientific models are typically less significant. Based on internal combustion engines as a physical phenomenon, people with varying experience in theoretical and practical traditions of knowledge, respectively, have been asked to interpret two computer animations. Originally, the study of combustion engines was motivated by the adoption of an STS (science, technology and society) approach to teaching physics and chemistry in secondary education. Initial data collection with natural science teachers and students were complemented by data collection with car mechanics teachers and students, representing a practical tradition, and vehicle system engineers, regarded as theoretical experts. This selection of informants reflects an ambition of showing a broader range of reasoning than what has been found in previous studies.

The tradition of knowledge in itself is not the only factor influencing the way models are interpreted. Other important factors are the previous experience of different types of representations and of particular models among the participants and their perceived aim of the data collection. However, in line with the view of France, et al. (2010) on the practice of the discipline, we claim that the role of different traditions of knowledge may provide an overarching perspective for analysis.

The present study addressed the following research questions: 
- What aspects of modelling are focused on in a theoretical or practical tradition of knowledge, respectively?

- How is the interpretation of two computer animations depicting models of a technical artefact and its function influenced by the level of experience in a theoretical or practical tradition of knowledge?

\section{Theoretical background}

\section{Traditions of knowledge}

Molander (2002) contrasts two traditions of knowledge, which have developed in parallel in the western society. The theoretical tradition of knowledge is probably best represented by the natural sciences. It emphasises theoretical knowledge (thinking, observation and experiments), where application is seen as a separate stage, after the formation of knowledge. The theoretical tradition of knowledge holds the "conviction that knowledge mirrors or copies reality (although with certain distortions)" and it is possible to formulate it in words or mathematical language. As a contrast, a more diverse range of practical traditions of knowledge are represented by, for instance, master craftsmen, architects or practicing musicians. Here, the focus is on practical knowledge, based on good examples, practice, personal experience and trial-and-error, where knowledge and application is seen as a whole. Finally, where the theoretical tradition of knowledge focuses on cognition and thinking, the practical traditions of knowledge encompasses perception involving the senses and the entire body in knowledge and learning.

Kuhn (1996) argues that shared exemplars are important tools for communication within a science community in the normal science stage. Exemplars are concrete, prototypical problems and their solutions, which are presented during education in a particular field. When encountering a new problem, an analogy can be made to a known problem and its appropriate problem-solving approach. This links closely to the original sense of the word paradigm, i.e. a grammatical pattern to follow for a given type of words, which Kuhn adopted in his description of science communities.

Technology and engineering sciences may be seen as holding an intermediary position between theoretical and practical traditions of knowledge, combining systematic research methods with practical purposes. Hendricks et al. (2000) point out that an overall difference is that in pure 
science the aim is to understand, related to the ontological question of what the world is like, whereas engineering science emphasises practical usefulness and efficiency. This difference is also expressed by Layton (1974):

The function of technological rules is to provide a rational basis for design, not to enable man to understand the universe. The difference is not just one of ideas but of values; "knowing" and "doing" reflect the fundamentally different goals of the communities of science and technology.

\section{Models and modelling}

Models can be seen as bridges between theory and the world-as-experienced. However, they come in many forms and can be used for several purposes. They can be simplifications, providing explanations of experienced real-world phenomena, but may also be generated from theories, in order to make predictions and compare with the real world through experiments. Scientific models may be resized representations of objects, such as scale models of viruses or the earth, or depicting abstract concepts, such as processes, mathematical relationships or systems with their interconnected components (Gilbert 2004). From a technological point of view, models are used for functional or practical purposes. The functional perspective represents the exploration of the technical feasibility: 'how to make it happen', and the practical perspective regards the sociocultural acceptability: 'should it happen?' (France et al. 2010).

Black (1962) categorises models in four different types, ranging from the concrete to the more abstract and theoretical:

- Scale models, preserving the relative proportions of an original. "We try to bring out the remote and unknown to our own level of middle-sized existence".

- Analogue models, which through a change of medium reproduce the structure or a web of relationships of the original. The aim is to establish point-by-point correspondences or, ultimately, an isomorphism between the original and the analogue. The challenge is to discern the corresponding features, as opposed to irrelevant surface characteristics.

- Through the use of mathematical models, a phenomenon is represented in mathematical terms. This involves the identification of relevant variables, formulation of hypotheses, simplifications to make calculations manageable, solving the formulated mathematical equations and formulation of predictions, suitable for empirical testing. However, the 
mathematical formulation cannot provide a causal explanation of the phenomenon studied.

- $\quad$ One of the key uses of theoretical models is that they can be a speculative instrument in the exploration of a new field, by analogy with a better known field. They can be used as a heuristic fiction, as if they were the reality, or, alternatively, as being the reality, aspiring to an ontological explanation.

\section{Dynamic visualisations}

Hegarty (2004) notices that there has been a lot of enthusiasm for the possibilities of dynamic visualisations enabled by increasingly powerful technology in education. However, initial studies have failed to establish a clear-cut advantage in learning effectiveness over the use of static media. She explains that in the following second phase of research, the objective is to establish under what conditions dynamic visualisations are effective.

One dimension of interest is the degree of realism. Often, animations portray a prototypical item, with detailed features and interactions similar to a motion picture of the object. However, visualisations can also be used for more abstract phenomena, not visible to the naked eye, such as moving molecules, weather systems, or graphs showing relations between quantities. Hegarty (2004) explains that this kind of abstraction or even distortion of reality may be more useful for knowledge construction than more realistic animations.

Dynamic visualisations can also be classified according to the degree of interactivity. Noninteractive animations are similar to a video clip, where you watch it at a fixed pace and duration. Interactivity can be introduced by allowing the user to manipulate the pace, freeze the image, alter quantities involved to simulate scenarios or select the information being displayed, etc. The rapid changes of images in non-interactive animations may be more challenging to take in than corresponding still images, where the details can be taken in during the time required. In addition, the learner may be less active, since the sequence of the images displayed are decided by the animation. However, allowing the user to interact with the dynamic visualisation adds other challenges, such as learning the functions of the user interface (Hegarty 2004).

One of the animations used in this study was developed by Christian and Belloni at Davidson Collage within the Physlets ${ }^{\circledR}$ framework. Physlets ${ }^{\circledR}$ are interactive computer animations in the form of Java applets, which cover the introductory university physics education, combined with 
instructional design. They have been designed to show abstract phenomena, force the learners to reflect and adopt more effective problem-solving strategies than typically used for text-book examples, and combine several modes of display, such as images, graphs and values of physical quantities (Cox et al. 2003b). In an analysis of the Physlets® framework, Krusberg (2007) found that it adheres well to the field of conceptual understanding in science education research. Students are instructed to make predictions before working with the animations, a meta-cognitive process where preconceptions and possible misconceptions are articulated. Often, the animations show phenomena which conflict with the preconceptions, in line with the cognitive conflict approach in conceptual change research, followed by scientific explanations of the phenomena. In addition, the animations are designed to develop the ability to translate across different representations of the phenomena. Finally, the instruction is based on student cooperation.

\section{Combustion engines}

The Otto engine is the most common type of internal combustion engine in vehicles powered by petrol. It works in a cyclical manner, with four distinct phases or strokes as ideally depicted in Figure 1 below, thereby being a four stroke engine. The main feature of the Otto principle is that a compressed mixture of petrol and air in a gas chamber is ignited by a spark plug, which makes the fuel and oxygen in the air react, so that combustion takes place. In the combustion, energy is released from the chemical bonds and the temperature of the gas increases. As a result the gas can exert work on a piston as the gas expands and the pressure decreases during the power stroke (1), which propels the vehicle. Exhaust gases are let out during the exhaust stroke (2), and fresh air and petrol is taken in during the intake stroke (3), phases during which valves are open and the gas in the gas chamber has approximately atmospheric pressure. During the compression stroke (4), which closes the cycle, the mixture of petrol and air is compressed by the piston, resulting in increasing pressure as the volume is reduced, but due to the lower temperature compared to that of the power stroke, the required work is considerably less, resulting in a net work performed by the engine.

The ideal Otto cycle can be used to represent the physical process of Otto engines. It is assumed that the gas in the chamber is ideal and evenly distributed at all times, regardless of the composition, so that the ideal-gas law applies and the heat capacity is constant throughout the process. The combustion reaction is assumed to occur instantaneously, thereby increasing the 
pressure and the temperature at constant volume in the beginning of the power stroke. The power and compression strokes are regarded as adiabatic processes, where no heat is exchanged with the surroundings. The ideal Otto cycle includes a number of simplifications. For example, in real engines, no processes occur instantaneously and without heat exchange. Figure 1 shows a PV diagram, i.e. the pressure against the volume, of the ideal Otto cycle.

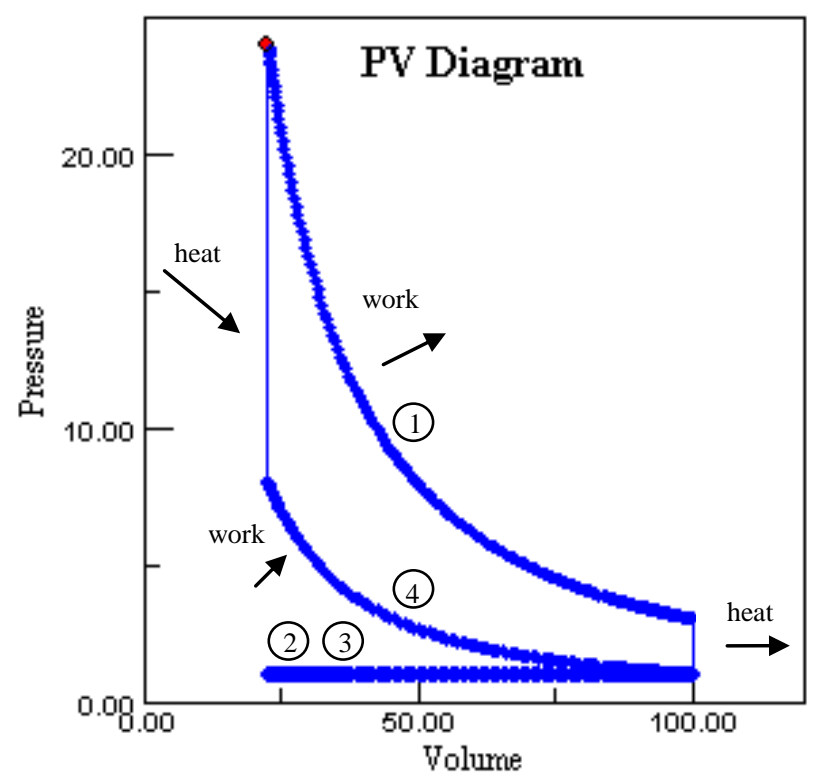

Figure 1. PV diagram of the pressure against the volume throughout the four strokes in an ideal Otto cycle. 1. Power stroke; 2. Exhaust stroke; 3. Intake stroke; 4. Compression stroke (Adaptation of image by Cox et al. 2003a).

A Diesel engine is another type of four-stroke engine. However, the gas in the cylinder during the compression stroke is not a fuel mixture, but air alone. At minimum volume and high compression, fuel is injected into the cylinder, and the mixture self-ignites because of the high pressure, not by the use of a spark plug, as in the case of the Otto engine. The ignition during start in cold weather is enabled by a glow plug, adding heat but without a spark.

\section{Method}

Since the interpretation of scientific models has not previously been analysed from the point of view of different traditions of knowledge, to the knowledge of the authors, the study was exploratory in character. Therefore, a bottom-up approach was assumed, where collected data was analysed in an inductive way, without an initial theoretical framework. This approach called for a flexible design, where new data and insight influenced the way forward, and new groups of 
informants were added one after another. In all, data was gathered in think aloud sessions with 19 informants, and the analysis was done in a qualitative way. With this exploratory approach, the ambition was to capture as broad a range as possible of different ways of interpreting two computer animations. As a consequence, data collection was conducted with informants representing several categories. The main aim was not to establish generalisable characteristics of the categories or differences between them, but to describe and interpret existing ways of approaching the animations. Another dimension of variation was to use two different animations. As seen below, one animation shares many characteristics of a scale model, while the other is a more idealised representation, including a PV graph of the ideal Otto cycle.

\section{Informants}

Data collection were first conducted with six natural science students at grade 12 (age 18) and three teachers (two in physics and one in chemistry) at an upper secondary school in Sweden. These informants were former students or colleagues of one of the authors, which presumably gave good conditions for an in depth analysis of the lines of reasoning, but also provided the risk of missing to point out the familiar and seemingly obvious. As a result of the tentative analysis, the initial data collection was followed by data collection with four vehicle mechanics students at grade 12 and two teachers in vehicle mechanics at another upper secondary school in Sweden. These sessions had the purpose of identifying lines of reasoning in a practical tradition of knowledge related to the animations, as a contrast to the theoretical natural science students and teachers. Finally, three $\mathrm{PhD}$ students and one MSc student specialising in vehicle systems engineering at a university in Sweden were studied. They represent a theoretical tradition of knowledge, but with the special pragmatic characteristics of the engineering sciences.

The aims of the natural science program are geared towards the introduction of the students in the theoretical tradition of knowledge of the natural sciences. Phenomena in nature are seen as an external object of study, which can be represented by mathematics and other abstract models. At the final year, the natural science students in the present study were expected to have basic understanding of the nature of science and central concepts in physics and chemistry, such as the ideal gas law and the chemical reactions of combustion. This particular group of informants had done thematic work on environmentally sustainable solutions for the car technology of the future prior to the study. However, they had a limited understanding of the principle of the internal 
combustion engine and related phenomena. The three teachers were specialising in either physics or chemistry and had no prior in depth knowledge of combustion engine technology.

The aims of the vehicle program are in line with practical traditions of knowledge, as described by Molander (2002). Here, the focus is on building competency in the trade of vehicle and aircraft maintenance, through know-how of measurement, error detection and repair. While Molander uses examples from masters in various forms of art, the vehicle program prepares for industrial occupations and emphasises the use of advanced technology which leaves less room for individual artistry. However, the car mechanics profession still has elements of the craft tradition. By the final year of their studies, the vehicles students in the study were expected to have a basic understanding of the combustion engine as a technical artefact and a growing intuition of what may work in the practice of car maintenance. They had experience of a set of individual cars and car engines as exemplars, if Kuhn's (1996) term is extended to cover also non-science communities. Apart from their role in education, the teachers in the study were experienced car mechanics.

The MSc and $\mathrm{PhD}$ students in vehicle system engineering were training to become experts in combustion engine modelling. From a science point of view, they had taken courses in thermodynamics and statistical physics at undergraduate level. As part of their specialisation, they had encountered theories and models of increasing level of refinement of the function of internal combustion engines. Particularly, they had studied the ideal Otto cycle, which is represented in the interactive animation of this study, but also how it can be modified in order to model the phenomenon in a more accurate way, with less radical idealisations. Here, the ideal Otto cycle is an exemplar in Kuhn's (1996) sense. In their pragmatic engineering science tradition, as described by Hendricks et al. (2000), the aim is to get engines to work in the most efficient and reliable way possible, but with access to powerful research tools, such as computer simulations and experimental design. Innovation and creativity are more important features than at the vehicle program, but the practical know-how of the engineers may be less advanced that of the vehicle program students and teachers.

Table 1 gives an indication of the assumed level of experience among the informants in each category and can be regarded as a basis for selection of the informant categories, although the sessions revealed some variation also within the categories. 
Table 1. Description of informants in each category and classification of their assumed experience, as basis for selection of informants.

\begin{tabular}{|l|l|l|l|}
\hline $\begin{array}{l}\text { Informant } \\
\text { category }\end{array}$ & $\begin{array}{l}\text { Experience of traditions } \\
\text { of knowledge }\end{array}$ & $\begin{array}{l}\text { Experience of physical } \\
\text { engines }\end{array}$ & $\begin{array}{l}\text { Experience of ideal } \\
\text { Otto cycle model }\end{array}$ \\
\hline Science students & $\begin{array}{l}\text { Limited (theoretical } \\
\text { tradition) }\end{array}$ & Limited & Limited \\
\hline Science teachers & $\begin{array}{l}\text { Extensive (theoretical } \\
\text { tradition) }\end{array}$ & Limited & Limited/Intermediate \\
\hline Vehicle students & $\begin{array}{l}\text { Limited (practical } \\
\text { tradition) }\end{array}$ & Intermediate & None \\
\hline Vehicle teachers & $\begin{array}{l}\text { Extensive (practical } \\
\text { tradition) }\end{array}$ & Extensive & None \\
\hline $\begin{array}{l}\text { Engineering } \\
\text { PhD and MSc } \\
\text { students }\end{array}$ & $\begin{array}{l}\text { Extensive (theoretical } \\
\text { tradition)/ Limited } \\
\text { (practical tradition) }\end{array}$ & $\begin{array}{l}\text { Intermediate (primarily } \\
\text { theoretical perspective) }\end{array}$ & Extensive \\
\hline
\end{tabular}

\section{Data collection}

The data was collected using the think aloud method, an approach where the informant is asked to speak out any thoughts that come to mind, while performing an activity. It was developed from the introspection method in psychological research, in which subjects were asked to analyse and reflect upon their thought processes, but avoids the disadvantage of having the conscious mind analysing itself and assumes a mere verbalisation of the thoughts. The ambition is that the researcher should not interfere in the thought process and only encourage the informant to keep on talking if he or she remains quiet. This is difficult to achieve, since the researcher is tempted to put forward questions or prompt certain action in order to improve the problem solving and learning (Someren et al. 1994).

In the present study, the informants were shown two computer animations of Otto combustion engines (see Figure 2 below) in sequence. The think aloud method was modified so that the stretches of think aloud talking were complemented by follow-up questions from the researcher on unclear issues and, for instance at the end, how they would like to improve the animations for deeper and quicker understanding. Although this may have interrupted or influenced the informants' thinking process, it was considered as useful in the subsequent analysis of the data. The sessions were performed at the informants' schools or university and 20-35 minutes in length. They were video recorded and transcribed in verbatim. The sessions with the vehicle students and teachers were performed by the two researchers and the remainder by one of the researchers. 

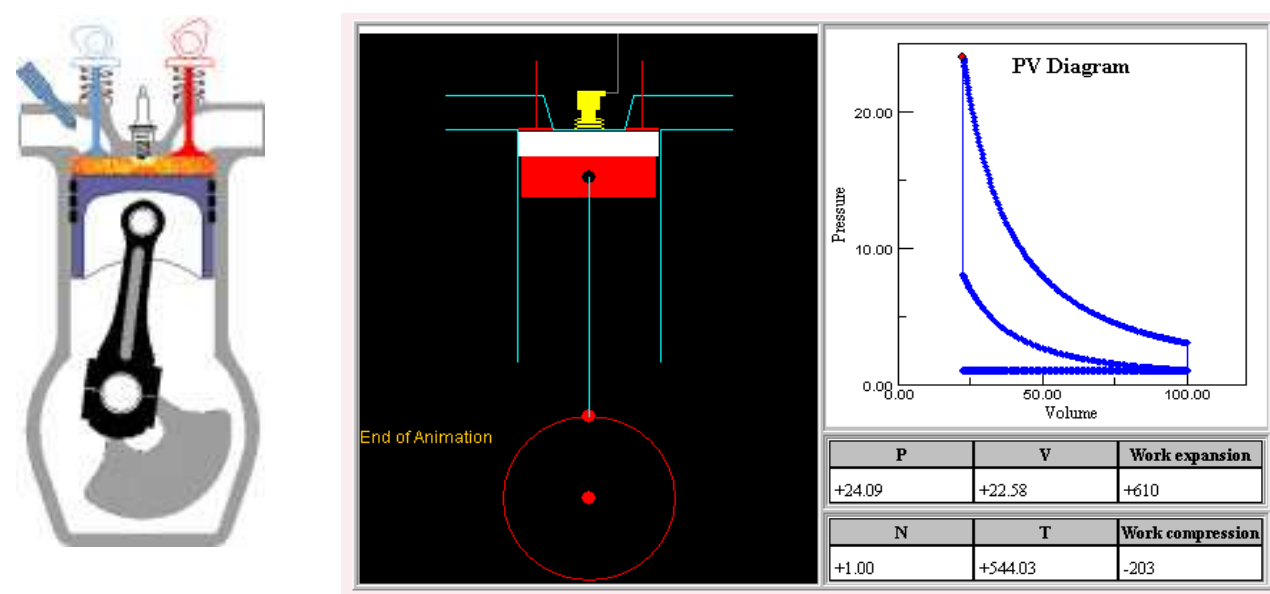

\begin{tabular}{|l|l|l|l|}
\hline play & pause & step $>$ & reset \\
\hline
\end{tabular}

Figure 2. Animations used in the data collection sessions: Detailed animation, left (TIMLOTO 2007); interactive animation, right (Cox et al. 2003a).

\section{Instruments used}

The detailed animation (Figure 2, left), which was shown first, is a dynamic two-dimensional cross-section representation of a cylinder of an Otto engine. The animation shows continuous motion with a fixed cycle time of about 3 seconds. It cannot be adjusted by the user, but has the character of an animated video clip.

The cylinder is positioned vertically, with the piston below the gas chamber. It is detailed in the respect that components, such as spark plug, crankshaft, piston, valves and camshafts are depicted as extended objects. The interaction of the parts during motion is shown in a clear way, although no mechanism is shown linking the rotation of camshafts and the crankshaft, nor where fuel and gases come from or go to afterwards.

The colours, particularly of the gases and fuel, are carefully selected, representing types of substance and temperature. Injected fuel is green, and the mixture of fuel and air is turquoise. When the combustion takes place, the colour of the gas mixture turns into red and yellow, which is kept during the power stroke, possibly with the percentage of yellow increasing somewhat. During the exhaust stroke, the gas is grey. The intake valve and corresponding camshaft are blue and the exhaust valve and camshaft are red, indicating the different temperatures of the related gases.

In Black's (1962) classification, the detailed animation shares most characteristics with a scale model, since it keeps the shapes, relative position and motion of the components, although in a $2 \mathrm{D}$ representation. The colour scheme is adapted to emphasise the changes of substance and temperature and the animation shows one cylinder in isolation, as a subsystem of an engine. The 
animation is quick, which makes it difficult to discern some of the fine details. Along Hegarty's (2004) dimensions of level of realism and interactivity, the detailed animation is highly realistic and with no interaction.

The interactive animation (Figure 2, right) is also a dynamic representation of a cylinder of an Otto engine, developed in the Physlets ${ }^{\circledR}$ suite described above and intended for teaching in introductory university physics. It comprises three synchronised parts: One cross-section drawing of the cylinder, similar in function to that of the detailed animation; one PV diagram, showing how the pressure varies with the volume during a cycle, and; physical quantities with values. The interactive animation has a cycle time of 39 seconds.

In the drawing, the cylinder is positioned vertically, with the piston below the gas chamber, as in the detailed animation. The details are more schematic, however, showing thin stick figure representations of the components. The colour of the content in the cylinder is different in the four strokes, but not with a clear symbolism such as corresponding to temperature. Another difference is that every stroke is accompanied by a small caption, telling for example 'expelling exhaust gases' during exhaustion, inserted in the drawing. The PV graph shows the pressure as a function of the volume of an ideal Otto process, in synchronisation with the drawing. The graph is shown as a rather thick, blue line throughout the process. 'Pressure' and 'Volume' are labels of the axes, which have values, but without units. The isobaric processes during exhaustion and intake have different pressures, but very close to each other, so that the lines overlap partially. In the quantities section, the quantities P, V, N, T, 'Work expansion' and 'Work compression' are displayed with their values, in synchronisation with the drawing and the diagram. The quantity $\mathrm{N}$ represents $n R$, i.e. the amount of substance $(n)$ multiplied by the gas constant $(R)$, as told in a text below the three main parts of the animation. This is helpful, since $\mathrm{N}$ usually represents number of particles in thermodynamics. There is no text explaining what $\mathrm{P}, \mathrm{V}, \mathrm{T}$ and the work variables represent, and there are no units displayed for the values.

Using Black's (1962) classification, the drawing lies between a scale model and an analogue model, since the relative positions and motion of the components are kept, but with considerable simplifications of the shapes and sizes. The PV graph and quantities are mathematical models, which do not share visual similarities with an engine, and cannot be seen as isomorphic representations. Similarly, along Hegarty's (2004) scale of degree of realism, the drawing is 
slightly less realistic than the interactive animation, while the graph and quantities sections are highly abstract representations.

Along Hegarty's (2004) interactivity dimension, the interactive animation is moderately interactive. It can be paused by the user and stepped forward more slowly via a simple user interface. The values of the quantities, such as the pressure, cannot be varied, however. This moderate level of interactivity may be conducive to learning, since it gives some user control, but requires negligible focus on the interaction.

\section{Data analysis method}

The data collection sessions were transcribed and the data was analysed through a bottom-up approach, where patterns and themes in the data were sought for, without the commitment to a specific theoretical framework prior to the study. The focus on views of scientific modelling and different traditions of knowledge evolved in an iterative fashion during the study. The reasonableness of the interpretations of the statements from the informants was reinforced by analysis performed by both researchers separately, yielding consistent interpretations. The inclusion of extensive data excerpts in the results section below gives the possibility to make alternative interpretations.

\section{Results}

The results presented below are categorised along the two main identified themes: the interpretation of the relationship between models and underlying physical phenomena, and; the informants' assessments of the usefulness of the animations. The presentation is based on illustrative, strategically selected excerpts, followed by analysis of the lines of reasoning against the theoretical background.

\section{Relationship between model and phenomenon}

All 19 informants, except one natural science student, identified the two animations as representations of combustion engines, depicting the same phenomenon. In the detailed animation, they were able to identify the basic function of the engine, which provided a starting point for communication. However, the level of detail in the descriptions varied considerably. When asked, S7, one of the vehicle students pointed out the following components: 
S7: OK. An exhaust valve [points to the right], an intake valve [points to the left], injector, a piston [points down], connecting rod, crankshaft, and this would be the cylinder head... [points to the right] and the cylinder in here [points to the middle], spark plug, valve springs, camshafts [points to the top]. Here, the air comes in [points top left], then it gets compressed... goes 'bang', so that it gets the crankshaft going... then it pushes it [the gas] out of the exhaust valve. /.../ Then there are piston rings down here [points to the middle], tightening the crankcase, so that things do not get down there... so that compression is kept up all the time.

S7 used an accurate vocabulary and showed a remarkable attention to details. Component for component, he made sure that the detailed animation matched his understanding of a real Otto engine. For instance, he was the only participant commenting on the piston rings, which were very small in the detailed animation and difficult to perceive.

The PhD students were familiar with the PV graph of the ideal Otto cycle, and how it can be refined. P2 commented on the graph at the end of the interactive animation when combustion starts:

P2: We have come here in our volume pressure diagram... and at this point [points at left in the graph], when we go straight up, we combust in this... all ideal assumptions... we say that all gas burns at once, which maybe really would be more of an explosion... that everything is combusted and all energy released.../.../ which we see when we take a large step up [points upwards] in pressure... but in a real engine, this combustion takes time... it takes a certain movement of the piston... so, a real pressure diagram would be much more rounded [points at the top of the diagram]. /... And this is a simplified assumption in many ways... just that it goes straight down like that and straight up... that is nothing you would see if you measured it in the lab... /.../ When you have this... heat transfer to the walls... finite burn times... that the gas burns... so there are a lot of assumptions you have to make about this process before you get a diagram like this one... So that, at the same time, you can adopt this rather simple model by including scale factors.../.../ And then you may have to scale how much work you get out when you expand the gas... you may have to include a scale factor, corresponding to some heat transfer... that you have a burning time and that you have differing slopes on this PV to the power of gamma equals constant.../.../ That the gamma differs a bit, and such.../.../ So you can get quite far with a very simple analysis, really. 
P2 knew how to interpret the graph and he was aware of the idealisations made. In addition, he discussed how the model could be improved in order to depict the pressure and volume of a physical engine, taking into account non-ideal phenomena such as heat transfer. There was an underlying assumption that the process can be represented by many different models of different degree of sophistication. These are all characteristics of the expert view of modelling in the framework by Grosslight et al. (1991) and in Justi and Gilbert's (2003) descriptions, but also of the theoretic tradition of knowledge. Another of the $\mathrm{PhD}$ students proposed the use of a diagram showing the pressure of the cylinder as a function of the crank angle (the angle of the crankshaft). This is another example of the willingness to use different models to represent the process, but also shows the familiarity with the field of combustion engine modelling, where the ideal Otto engine is a shared exemplar. In addition, while the PV graph representation is shared between the science field of thermodynamics and vehicle engineering, the depiction of functions of the crank angle are exclusively used in engineering, with a particular technological focus on the function and efficiency of the engine in terms of exact moments of opening and closing of the valves and ignition.

Below, T5, one of the teachers at the vehicle program had identified that the quantity $\mathrm{T}$ represents the temperature in the interactive animation and analysed the values throughout the cycle:

T5: [intake stroke] We have constant temperature there... It seems a bit strange... [compression stroke] During the compression stroke there, the temperature increases. That seems OK. [animation ends] And there, it ends up just before... well, in that case it should be in Celsius... that could be OK, I guess... but why doesn't it change during the other strokes, then? /.../ I mean, when we get to the intake stroke, it should cool down considerably in the cylinders... otherwise, it seems all right...

I: Why is it, do you think, in this graph, that it is constant? /.../

T5: No, I don't dare to guess, really... well, they could have preheated the air then [during intake], in that case... so a certain temperature, then... but during the exhaust stroke, I have no guess... / .../ Is there something I have missed? [laughs]

T5 showed that he understood the phenomenon and knew how the temperature typically would vary throughout the process. When he recognised that the PV graph was not plotted in accordance 
with his understanding, his reaction was to search for ways to adjust the engine to the model, as if asking what kind of contraption would fit the shown pattern. He came up with the creative solution of preheated air, but was not very enthusiastic (possibly because preheating would decrease the efficiency of the engine). He tried to fit the world into the model, instead of regarding the model of the engine as a rather crude representation and criticising the unrealistic idealisations made. It also seems to fit well with the work of the skilled mechanic of detecting and diagnosing errors and finding the most effective way of dealing with them and achieving the desired functioning of the engine. When he saw an unexpected and puzzling shape of a graph, he tried to identify the reason behind the pattern. Alternatively, the possible effect of being polite towards the researcher by not criticising the model should not be ignored, though.

Also P2, the PhD student, gave an example of fitting the phenomenon to the model, when interpreting the constant pressure during intake and exhaustion. Only when giving the engine full gas, the model would be a reasonable representation:

P2: They have assumed that it is the same pressure here on the intake side as on the exhaust side... which would correspond to full gas of the engine, that the throttle is entirely open... otherwise, you could have seen another decrease in pressure... because they had closed the throttle a bit... that the air flow had been limited... have had lower pressure in this pipe [pointing to the intake].

While the PhD student and vehicle teacher in the excerpts above realised that there was a rather poor fit between the model and the phenomenon, other informants showed a limited understanding of the animations and what they depicted. For instance, S3, one of the natural science students, recalled having seen similar animations before. However, he failed to recognise it as the cylinder of a combustion engine, but rather saw the interactive animation as some kind of pump, through which a liquid flowed. He interpreted the blue colour of the fluid coming in as a liquid, instead of the intended gas at low temperature. This failure to connect the model to the intended phenomenon was probably due to limited experience of both the phenomenon and the model. Eventually, he realised his misinterpretation, when he was directed to the colours and looked at the red and yellow colour coding of the ignited fuel. This is the only informant that failed to identify one of the animations as a representation of a combustion engine. Other informants made slight misinterpretations, such as one of the vehicle students taking the animations for Diesel engines. However, all informants in the study realised that the two animations represented the same 
physical phenomenon, which indicates that that they noticed the shared structures of the models, and not only surface features.

Another way of approaching the relationship between the model and the phenomenon was to point our the boundaries between the model as a subsystem and the engine as a whole. For instance, S2, one of the natural science students, commented that that there would have to be another cylinder working out of synch and driving forward the represented cylinder during compression. In real life, one cylinder engines are feasible, with the compression being done by the inertia of the crankshaft, possibly attached to a flywheel, but the balancing of several cylinders gives smoother running and is the typical set-up in car engines. PhD student P2 also wanted to put the model in a broader context, and proposed that the model could be improved by showing additional components, such as the catalyser, which would help understanding why the pressure is not 1 bar consistently when the valves are open.

In the sequence below, one of the vehicle teachers, T4, had established that $\mathrm{P}$ measures the pressure in the interactive animation:

I1: Would you dare to give a unit... or what is it they measure here?

T4: Let's see... It should be down here, then... 3.5... run it, so we'll see... [full run of the animation] Well, what pressure could it be...? Bars, maybe? [points to compression in the graph] now, I thought of the compression pressure... when it was... but now, it jumped up, maybe, to... up there... [points to 24 mark on the pressure scale] /.../ Well, then it doesn't make sense... with bars. /.../ when combustion starts, the pressure is considerably higher than 24 bars... On the other hand, if it had been the compression pressure, it could have been a Diesel engine...

T4 knew reasonable values of different types of engines throughout a cycle and used this knowledge in the analysis of the PV graph. In his practical tradition of knowledge, he used concrete experiences of individual engines and his knowledge of engine types for comparison in his interpretation. Similarly, S9, one of the vehicle students, used rules of thumb in the analysis of the $\mathrm{P}$ variable:

S9: Yes. What could this be? [exhaustion starts] There it is still, yes... [compression starts] and there it starts to move... what the heck could it be...? [end of animation] it feels as if it could have something to do with the pressure... but anyway... 24 feels a bit high... [starts animation] It could be a Diesel, in that case... 
I1: Why do you feel that it is high?

S9: No, I mean... for a petrol engine, it is usually around 12,15 , something... it feels as if 24 is high for a petrol engine... [exhaustion] but here, it stands still... that is atmospheric pressure, I assume... 1.10...

The knowledge of reasonable pressure values is useful for car maintenance, because the physical measurement of compression pressure of the cylinders of an engine is a main diagnostic tool for identification of problems and may provide suggestions of how they can be resolved. S9 assumed that the unit of pressure is 1 bar or 1 atmosphere, which he was used to in the education.

\section{Informants' assessments of the aptness and use of the models}

Many of the informants, both students and teachers, expressed that both animations had some merits, particularly when used together in sequence. The detailed animation was found to give a good, realistic view of what an engine looks like and its function, while the interactive animation gave insight into the physical quantities involved. Due to the sketchy character of the interactive animation, a certain understanding of the process would be needed as a prerequisite to be able to use it. Several of the informants proposed to merge the animations in order to get the realistic features and logical colour coding of the detailed animation, and the interaction, slow speed and PV graph of the interactive animation. In addition, they requested information on what the quantities of the interactive animation represented and their units. T3, one of the science teachers, compared the animations:

T3: Well, this one [the detailed animation] explains the phenomenon in a better way, really... you see... the petrol runs in ... the blue is the petrol... the petrol runs in... we get an explosion... [points to the cylinder] it gets red.../.../ The other [the detailed animation] is more practical, really... this [the interactive animation], more mathematical... you could say, well... it's more... this [the interactive animation] is more of a model... /.../ The other [the detailed animation] is more reality, in fact... the actual car, the cylinders, the pistons... it works like that. /.../ It [the interactive animation] is more from a mathematical point of view.

I: If we take that word, model... why is it that this [shows the detailed animation] is not a model, in that case?

T3: No, this is a model, too... but it is more real than the other, actually... 
Here, T3 said that the detailed animation was more realistic than the interactive animation and a representation closer to the phenomenon. As seen in the analysis of the animations above, the interactive animation uses simplification, abstraction and a mathematical representation, all characteristics of the theoretical tradition of knowledge in Molander's (2002) sense. They are also characteristics of scientific models and therefore, T3 perceived the interactive animation as 'more of a model'.

T5, one of the vehicle teachers, was used to seeing graphs of the cylinder pressure as the result of measurement of individual physical engines and error-tracking if they would show an unusual pattern. In his practical tradition of knowledge, there is no need to distance away from the technical artefacts and make simplifying abstractions and generalisations. In the following evaluation of the animations, he questioned their usefulness:

I2: But do you think that animations like this would add anything to the education?

T5: Well, we already have them. /.../ we have video films of the Otto engine and the Diesel engine. Where you run it at slow speed... We have that, so there is nothing [new]... and a lot... [laugh] you have to apologise... these are not yours, I understand, but they [the videos used in education] are... /.../ nicer and... yes, nicer. And with a speaker text... so, at first, you maybe run it a bit... a bit quicker... then you take it step by step.

T5 argued that the existing use of video films of engines is a better option than the animations of the present study at his level of teaching, the upper secondary school vehicle program. Apart from the scaling of the speed, the video films are representations that are as realistic as possible, which was seen as an advantage. Distortion, on the other hand, by emphasising certain features and overlooking others, one of the characteristics of modelling in the theoretical tradition of knowledge, was seen as a disadvantage. Some of the students, particularly vehicle students, found the interactive animation challenging to follow and preferred the detailed animation. Their teacher T5 explained:

T5: That one [the detailed animation] is easier to understand, right...? Normally... the other one [the interactive animation] gets... well, when you have two things to try to concentrate on... that is bound to fail, so to speak.../.../ But you have to take things one by one... and separate one from the other... and look at them one by one.../.../ 
This [the detailed animation] is the basic school and that [the interactive animation] is more advanced studies.

While the detailed animation shares many of the characteristics of video films, T5 saw that the complexity of the interactive animation would be too high for his vehicle students. This is not surprising, since it was designed for university teaching in physics. The main point, however, is the opinion that the more realistic the representation is, as in the form of a video clip of a physical engine, the better it would be, from the view of this practical tradition of knowledge.

\section{Discussion}

As a conclusion, the generalisation and idealisation aspects of modelling are focused on in theoretical traditions of knowledge, while naturalistic representation of individual physical exemplars characterise the modelling in practical traditions of knowledge. As a consequence, idealised models are found to be confusing and of limited value in a practical tradition of knowledge. In particular, the $\mathrm{PhD}$ students as experts in the theoretical tradition of knowledge were more familiar with and more positive towards the interactive animation, built on the ideal Otto cycle, compared to the vehicles teachers as experts in a practical tradition of knowledge. This is partly due to the direct experience of the ideal Otto cycle as a shared exemplar throughout their education. It is also related to the characteristic of the theoretical tradition of knowledge of making generalisations and idealisations from exemplars in real life, whereas the vehicle teachers preferred to show a more realistic representation of one concrete exemplar of an engine. The natural science teachers, as other representatives of the theoretical tradition of knowledge, shared this generally positive attitude towards the interactive animation, although the ideal Otto cycle was not a generally known exemplar in this group of science teachers. While France et al. (2010) point out that modelling is crucial in both science and technology, although for different purposes, the vehicle teachers represent another practice or tradition where this is not the case.

The PhD students and the vehicle teachers realised that the ideal Otto cycle is a crude model of a combustion engine. However, they dealt with this in qualitatively different ways. Where one of the vehicle teachers tried to fit the world into the model, as if asking what strange engine this is, the $\mathrm{PhD}$ students were aware of the idealisations made in this particular model. The vehicle teacher searched in his memory among his experienced exemplars in the form of concrete engines he had encountered, but failed to find a match. Both these ways of coming to terms with the issue 
are in our view competent ways of reasoning, however based on different experiences within different traditions of knowledge.

Although the two traditions of knowledge can deal with the same physical phenomenon, in this case car engines, they do it with different perspectives and purposes. A parallel was pointed out already by Aristotle (1984):

For a carpenter and geometer investigate the right angle in different ways; the former does so in so far as the right angle is useful for his work, while the latter inquires what it is or what sort of thing it is; for he is a spectator of the truth.

Potentially, characteristics of the two types of tradition of knowledge can be singled out, but as a representative of the pragmatist view, Dewey (1916) emphasises that theory and practice always go together. There is a practice of making science and, as Lewin (1952) noted, "there is nothing more practical than a good theory". The other way around, 'learning by doing' requires purposeful action and reflection in order not to be reduced to just doing. Theoretical and practical traditions of knowledge may be seen as end points of a continuum, where the pragmatic engineering sciences are found midway.

Through adopting an exploratory approach, the ambition of the study has not been to establish generalisable characteristics of the studied categories of people, but bring to the attention possible and existing ways of approaching computer animations of physical phenomena and artefacts. Hopefully, the results may stimulate to future studies using a more fixed design and may be useful for hypothesis generation. For instance, do people in practical knowledge traditions consistently adapt phenomena to a model, while people in theoretical traditions try to fine-tune the model after the phenomena?

By the use of a two-dimensional framework, rather than linear novice/expert comparisons, this study has strived for showing a more diverse range of reasoning. The ambition has been to give examples of many different, competent ways of interpreting and using a representation. In spite of the diversity, the general competence is shown by the fact that all informants saw the two, quite different animations as representations of the same phenomenon, each with advantages and drawbacks and useful for different purposes, and most of them linked the animations to the correct physical artefacts. This competence implies that they have come quite far from the simplistic view of 'models as toys', expressed by Harrison and Treagust (2000). 


\section{References}

Aristotle (1984). The Nicomachean ethics (D. Ross, Trans.). New York, NY: Oxford University Press.

Black, M. (1962). Models and metaphors: studies in language and philosophy. Ithaca, NY:

Cornell University Press.

Cox, A. J., Belloni, M., Dancy, M., \& Christian, W. (2003a). Otto engine.

http://webphysics.davidson.edu/physlet resources/thermo_paper/thermo/examples/otto_engine.ht ml. Accessed March 232010.

Cox, A. J., Belloni, M., Dancy, M., \& Christian, W. (2003b). Teaching thermodynamics with Physlets ${ }^{\circledR}$ in introductory physics. Physics Education, 38(5), 433-440.

Dewey, J. (1916). Democracy and education: An introduction to the philosophy of education. New York, NY: McMillan.

France, B., Compton, V. J., \& Gilbert, J. K. (2010). Understanding modelling in technology and science: the potential of stories from the field. International Journal of Technology and Design Education, doi:10.1007/s10798-010-9126-4.

Gilbert, J. K. (2004). Models and modelling: routes to more authentic science education.

International Journal of Science and Mathematics Education, 2(2), 115-130.

Grosslight, L., Unger, C., Jay, E., \& Smith, C. L. (1991). Understanding models and their use in science: conceptions of middle and high school students and experts. Journal of Research in Science Teaching, 28(9), 799-822.

Harrison, A. G., \& Treagust, D. F. (2000). A typology of school science models. International Journal of Science Education, 22(9), 1011-1026.

Hegarty, M. (2004). Dynamic visualizations and learning: getting to the difficult questions.

Learning and Instruction, 14, 343-351.

Hendricks, V. F., Jacobsen, A., \& Pedersen, S. A. (2000). Identification of matrices in science and engineering. Journal for General Philosophy of Science, 31(2), 277-305.

Justi, R. S., \& Gilbert, J. K. (2003). Teachers' views on the nature of models. International Journal of Science Education, 25(11), 1369-1386.

Krusberg, Z. A. C. (2007). Emerging technologies in physics education. Journal of Science Education and Technology, 16, 401-411.

Kuhn, T. S. (1996). The structure of scientific revolutions (3rd ed.). Chicago, IL: The University of Chicago Press.

Layton, E. T. (1974). Technology as knowledge. Technology and culture, 15(1), 31-41.

Lewin, K. (1952). Field theory in social science: Selected theoretical papers by Kurt Lewin. London, UK: Tavistock.

Molander, B. (2002). Politics for learning or learning for politics? Studies in Philosophy and Education, 21(4-5), 361-376.

Rossouw, A., Hacker, M., \& de Vries, M. Concepts and contexts in engineering and technology education: an international and interdisciplinary Delphi study. International Journal of Technology and Design Education, 1-16, doi:10.1007/s10798-010-9129-1.

Someren, M. W. v., Barnard, Y. F., \& Sandberg, J. A. C. (1994). The think aloud method. A practical guide to modelling cognitive processes.

http://www.cogdevelopment.com/courses/literature/Think-aloud-method.pdf. Accessed February 162009.

TIMLOTO (2007). motor_wout3.gif. http://www.timloto.org/pictures/motor_wout3.gif Accessed March 232010. 